\title{
Foods and drinks for sale in vending machines in two hospitals: progress made but room for improvement
}

\author{
J. Kan ${ }^{1,2}$, R. Matson ${ }^{2}$, K. Ingarfield ${ }^{2}$, A. James ${ }^{2}$, L. Birch ${ }^{2}$, P. Fletcher ${ }^{3}$, C. Boyce ${ }^{4}$, \\ J. Hamilton-Shield ${ }^{2}$ and F.E. Lithander ${ }^{2}$ \\ ${ }^{1}$ Faculty of Health Sciences, University of Bristol, BS8 1TH, ${ }^{2}$ NIHR Bristol Biomedical Research Centre (Nutrition \\ Theme), BS2 8AE, ${ }^{3}$ Department of General and Old Age Medicine, Cheltenham General Hospital, GL53 7 AN and \\ ${ }^{4}$ Department of Clinical Strategy, Cheltenham General Hospital, GL53 7 AN.
}

NICE Quality Standard 94 (QS94) identifies NHS venues as important settings in which to implement childhood obesity prevention strategies $^{(1)}$. In July 2016, we assessed two District General Hospitals in England and found that neither adhered to quality statement 1 of NICE QS94 ${ }^{(2)}$, which refers to the healthfulness of foods and drinks in vending machines. The aim of the current study was to assess the same vending machines 19 months later, after publication of our data collected in July $2016^{(2)}$ and following informal discussions with relevant individuals in the hospitals studied.

The Nutrient Profiling Model (NP) ${ }^{(3)}$ was used at both time-points to classify foods and drinks available as either healthy or less healthy. A food was classified as less healthy where it scored $\geqslant 4$ points and a drink was classified as less healthy where it scored $\geqslant 1$ point.

There was no significant improvement in NP scores for all foods between time-points $(18.3 \mathrm{vs} 16 \cdot 7, p>0 \cdot 05$, Table 1$)$. Both hospitals however made improvements in foods for sale in the vending machines, for instance crisps were replaced with 'low-calorie' crisps, though these scored $\geqslant 4 \mathrm{NP}$ points. Chocolate, sweets and biscuit items remained similar. Whilst there was no significant improvement in NP scores for drinks $(0 \cdot 5$ vs $-0 \cdot 3, p>0 \cdot 05$, Table 1) there were more healthier drinks available for purchase in February 2018.

Table 1. Numbers of foods and drinks and mean (SD) NP scores at both time-points in both hospitals

\begin{tabular}{lcc}
\hline & July 2016 & February 2018 \\
\hline $\begin{array}{l}\text { No. vending machines } \\
\text { Foods }\end{array}$ & 18 & 19 \\
No. of foods available & 40 & 39 \\
No. (\%) of foods classified as healthy & $4(10)$ & $5(13)$ \\
NP score of foods classified as healthy & $-1 \cdot 3(4 \cdot 5)$ & $1.4(1.5)$ \\
NP score of foods classified as unhealthy & $20 \cdot 5(6 \cdot 8)$ & $19(7 \cdot 6)$ \\
Drinks & & 15 \\
No. of drinks available & $8(53)$ & $14(93)$ \\
No. (\%) of drinks classified as healthy & $-0.5(1.4)$ & $-0 \cdot 4(1 \cdot 1)$ \\
NP score of drinks classified as healthy & $1 \cdot 7(0 \cdot 5)$ & $2($ N/A)* \\
NP score of drinks classified as unhealthy & & \\
* only one data-point hence no SD available & &
\end{tabular}

In conclusion, using the data collected in July $2016^{(2)}$, both hospitals have made improvements in the healthfulness of the foods and drinks for sale in their vending machines. Education could be provided in future to ensure that replacement foods in particular are classified as healthy, and could include items such as dried fruit and nuts, baked crisps, and raw nuts.

1. NICE (2017) https://www.nice.org.uk/guidance/qs94.

2. James A, Birch L, Fletcher P, et al. (2017) BMJ Open 7, e018214

3. Department of Health (2011) https://www.gov.uk/government/publications/the-nutrient-profiling-model. 